\title{
PRESCRIPTION AUDITING IN REGARD WITH THE PRESCRIPTION PATTERNS IN A TERTIARY CARE TEACHING HOSPITAL
}

\author{
Naveen $A^{1 *}$, Ramesh $B^{2}$, Siwani Teki ${ }^{3}$ \\ ${ }^{1}$ Assistant Professor, Department of Pharmacology, GIMSR, GITAM University, Visakhapatnam, India. ${ }^{2}$ Professor and HOD, Department of \\ Pharmacology, GIMSR, GITAM University, Visakhapatnam, India. ${ }^{3}$ II MBBS Student, GIMSR, GITAM University, Visakhapatnam, India. \\ Email: a.naveen.gmc@gmail.com \\ Received: 9 October 2017, Revised and Accepted: 8 November 2017
}

ABSTRACT

Objective: The study was undertaken to know the prescription patterns and to evaluate the rationality of prescriptions in regard with different parameters in a tertiary care teaching hospital.

Methods: This project was a non-interventional, cross-sectional, and observational study conducted at GIMSR Hospital after obtaining permission from Institutional Ethics Committee. A total of 500 prescription forms of the patients who visited the Outpatient Departments of GIMSR hospital, (GITAM University, Visakhapatnam) were recorded and evaluated for different parameters in consonance with the World Health Organization prescribing indicators. Results were analyzed and tabulated using simple statistical measures such as percentages and averages.

Results: We collected the data of 500 prescription forms of the patients who visited the hospital during July-August months of the year-2017. In this study, we observed that a total of 1127 drugs were prescribed. Therefore, average number of drugs prescribed per patient was found to be 2.25 . Results of prescription profile of the patients results are as follows, drugs prescribed by generic names only in $7.98 \%$ of cases, fixed-dose combinations were used in $15.7 \% \%$ cases, more than one antibiotic was prescribed in $04 \%$ cases, and $87 \%$ prescriptions were legible, $73 \%$ of prescriptions with complete diagnosis, and only $65.5 \%$ prescriptions were complete in terms of dose, route, strength, and frequency and dosage forms.

Conclusion: Our study suggests that there is an immense scope of improvement in prescription patterns in the hospital. Majority of drugs (92.07\%) were prescribed by the branded names, hence, there is an urgent need for prescription of drugs by generic names. Other parameters such as complete diagnosis and legibility of prescriptions need to be improved.

Keywords: Prescription patterns, Polypharmacy, Generic drugs, Fixed-dose combinations.

(c) 2018 The Authors. Published by Innovare Academic Sciences Pvt Ltd. This is an open access article under the CC BY license (http://creativecommons. org/licenses/by/4. 0/) DOI: http://dx.doi.org/10.22159/ajpcr.2018.v11i2.22983

\section{INTRODUCTION}

Medicines play an important role in health-care delivery and disease prevention. The availability and affordability of good quality drugs along with their rational use is needed for effective health care [1]. However, irrational drug use is prevalent, especially in the developing countries which have been considered as one of the most important factors for development of drug resistance. Furthermore, the World Health Organization (WHO) reports that more than half of all medicines are prescribed, dispensed or sold inappropriately, and that half of all patients fail to take them correctly.[2].

Prescription order is an important transaction between the doctor and the patient. The prescribing behavior of the doctor depends on the input from various sources such as patients, academic literature, professional colleagues, commercial publicity, and government regulations.

Various prescribing errors are result of the ineffective use of these inputs and are very common in clinical practices [3]. One of the most pressing problems facing public health providers and administrators in many countries is the irrational use of drugs [4].

Rational use of drugs is based on use of right drug, right dosage at right cost which is well reflected in the WHO definition: "Rational use of drugs requires that patients receive medications appropriate to their clinical needs, in doses that meet their own individual requirements for an adequate period of time, at the lowest cost to them and their communit" [5].

Worldwide, it is estimated that over half of all medicines are prescribed, dispensed or sold inappropriately, and that half of all patients fail to take their medicine correctly [6]. Irrational prescribing is a global problem. The rationality of prescribing pattern is of utmost importance because bad prescribing habits including misuse, overuse and underuse of medicines can lead to unsafe treatment, exacerbation of the disease, health hazards, and economic burden on the patients, and wastage of scarce resources. Therefore, prescription auditing plays an important role in evaluation/analysis of the prescriptions or case records of health-care setup. It is not only prevent further irrational prescribing habits but also makes prescribers accountable to their commissions and omissions. Hence, there is an immense scope for prescription auditing/auditors in different health-care settings.

\section{METHODS}

This project was a non-interventional, cross-sectional, and observational study conducted at GIMSR Hospital after obtaining permission from Institutional Ethics Committee. A total of 500 prescription forms of the patients who visited the Outpatient Departments of GIMSR Hospital, (GITAM University, Visakhapatnam) were recorded and evaluated for different parameters in consonance with the WHO prescribing indicators [7].

\section{Selection criteria}

- Inclusion: Only the prescription forms of outpatients were included in the study.

- Exclusion: The admitted patient's prescriptions or case records were excluded from the study, and also patients who were not willing to share their prescriptions were excluded.

The selected prescription forms were evaluated for prescribing patterns in consonance with the WHO indicators and other parameters 
such as age wise distribution of diseases and incidence. The WHO indicators are average number of drugs per encounter, percentage of drugs prescribed by generic names, number of fixed-dose combinations (FDCs), percentage of drugs prescribed from essential medicine list and different drug formulations, etc. All the prescription forms were analyzed accordingly, and results were tabulated using simple statistical measures such as percentages and averages. The WHO prescribing indicators were calculated as shown below.

\section{Prescribing indicators}

1. Average number of drugs per prescription: Average, calculated by dividing the total number of drugs prescribed by total number of prescriptions

2. Percentage of drugs prescribed by generic name: Percentage, calculated by dividing the number of drugs prescribed by generic name, by the total number of drugs prescribed, multiplied by 100 .

3. Percentage of antibiotics prescribed: Percentage, calculated by dividing the number of antibiotics prescribed by the total number of drugs prescribed, multiplied by 100 .

4. Percentage of injections prescribed: Percentage, calculated by dividing the total number of injections prescribed by total number of drugs prescribed, multiplied by 100 .

5. Percentage of drugs prescribed from essential drugs list: Percentage calculated by dividing the number of products prescribed which are listed on the essential drugs list or local formulary by total number of products prescribed multiplied by 100 .

6. Percentage of prescription with complete diagnosis, legibility with the signature of doctor present on the prescriptions.

\section{OBSERVATIONS AND RESULTS}

We collected the data of 500 prescription forms of the patients who visited the hospital during July-August months of the year-2017. Our study shown the following results, when we observed the demographic profile of the patients the study revealed that female patients were more in number (58\%) compared to male patients (42\%). With regard to age group majority of prescriptions (56.4\%) were belonged to $16-30$ years age group, then $14.4 \%, 11 \%, 11 \%$ belonged to $31-45$ years, $46-$ 60 years, and 1-15 years age group, respectively (Table 1 and Fig. 1 and Table 2 and Fig. 2), explain the aforementioned observations.

The observed disease pattern was variable. Diseases of the respiratory system were maximum $36 \%$ followed by diseases of gastrointestinal system $27 \%$ and diseases of musculoskeletal system $15.6 \%$. Diseases of cardiovascular system were $8 \%$, diseases of central nervous system were $6 \%$, diseases of endocrine system were $4 \%$, and infectious and parasitic diseases were $3.4 \%$ (Table 3 and Fig. 3) explain the above results.

If we observe the prescription profile of the patients the results are as follows, drugs prescribed by generic names only in $7.98 \%$ of cases. FDCs were used in $15.7 \%$ cases. More than one antibiotic was prescribed in $4 \%$ cases. Around $87 \%$ prescriptions were legible, $73 \%$ of prescriptions with complete diagnosis, and only $65.5 \%$ prescriptions were complete in terms of dose, route, strength, frequency, and dosage forms (Table 4 and Fig. 4) explain the above-mentioned parameters.

In this study, we observed that a total of 1127 drugs were prescribed. Therefore, average number of drugs prescribed per patient was found to be 2.25 . With regard to dosage forms, it was found that majority of drugs prescribed were oral (92.19\%) followed by injectables (3.37\%) and topical (4.43\%). Drugs prescribed from the National List of Essential Medicine 2015 were $97.07 \%$ (Table 5 explains about the dosage formulations). The most common drug groups prescribed were multivitamins, minerals, and enzymes $26.79 \%$, nonsteroidal anti-inflammatory drugs (NSAIDs) $21.29 \%$, antiulcer drugs $19.69 \%$, antibiotics $12.42 \%$, antihistamines $10.64 \%$, antiparasitic and antifungals $4.88 \%$, and expectorants and bronchodilators $1.15 \%$ (Table 6 and Fig. 5) explain about these details.
Table 1: Gender wise distribution of patients

\begin{tabular}{ll}
\hline Sex distribution & Number of prescriptions (\%) \\
\hline Males & $210(42)$ \\
Females & $290(58)$ \\
\hline
\end{tabular}

Table 2: Age wise distribution of patients

\begin{tabular}{ll}
\hline Age group (years) & $\mathbf{n}(\%)$ \\
\hline $1-15$ & $55(11)$ \\
$16-30$ & $282(56.4)$ \\
$31-45$ & $72(14.4)$ \\
$46-60$ & $55(11)$ \\
$61-75$ & $25(05)$ \\
Above 75 & $11(2.2)$ \\
\hline
\end{tabular}

Table 3: Disease pattern in patients

\begin{tabular}{ll}
\hline Disease pattern & $\begin{array}{l}\text { Number of } \\
\text { prescriptions (\%) }\end{array}$ \\
\hline Diseases of respiratory system & $180(36)$ \\
Diseases of digestive system (GIT) & $135(27)$ \\
Diseases of musculoskeletal system & $78(15.6)$ \\
Diseases of cardiovascular system & $40(08)$ \\
Diseases of central nervous system & $30(06)$ \\
Diseases of endocrine system & $20(04)$ \\
Infectious and parasitic diseases & $17(3.4)$ \\
\hline
\end{tabular}

GIT: Gastrointestinal tract

Table 4: Prescription profile of the patients

\begin{tabular}{ll}
\hline Parameters & $\begin{array}{l}\text { Number of } \\
\text { prescriptions (\%) }\end{array}$ \\
\hline Drugs were prescribed by generic names & $90(7.98)$ \\
FDCs used & $177(15.7)$ \\
More than one antibiotic prescribed & $20(04)$ \\
Complete diagnosis written & $365(73)$ \\
Legibility & $435(87)$ \\
Complete prescription in terms of dose, & $327(65.4)$ \\
route, strength, frequency and dosage forms & \\
\hline
\end{tabular}

FDCs: Fixed-dose combinations

Table 5: Drug dosage formulations profile

\begin{tabular}{ll}
\hline Parameters & Number of drugs (\%) \\
\hline Drugs on EML (2015) & $1094(97.07)$ \\
FDCs used & $177(15.7)$ \\
Dosage forms & $1039(92.19)$ \\
Oral & $38(3.37)$ \\
Injectables & $50(4.43)$ \\
Topical & \\
\hline
\end{tabular}

EML: Essential medicines list, FDCs: Fixed-dose combinations

\section{DISCUSSION}

The rationality of the scripts prescribed by physicians is of critical importance, since bad prescribing habits lead to ineffective and unsafe treatment, causing exacerbation or prolongation of disease and distress or harm to the patient, which adds an extra burden to health budgets of family and government.

The demographic profile of the patients of our study revealed that female patients were more in number (58\%) compared to male patients (42\%). With regard to age group majority of prescriptions $(56.4 \%)$ were belonged to the $16-30$ years age group, then $14.4 \%, 11 \%$, and 
$11 \%$ belonged to $31-45$ years, $46-60$ years, and $1-15$ years age group, respectively.

Table 6: Most frequently prescribed categories of drugs

\begin{tabular}{ll}
\hline Category of drugs & Number of drugs (\%) \\
\hline NSAIDs & $240(21.29)$ \\
Opioid analgesics & $35(3.1)$ \\
Antibiotics & $140(12.42)$ \\
Anti-ulcer drugs/GIT & $222(19.69)$ \\
Antihistaminics & $120(10.64)$ \\
Anti-parasitic and antifungals & $55(4.88)$ \\
Multivitamins, minerals, and enzymes & $302(26.79)$ \\
Expectorants and bronchodilators & $13(1.15)$ \\
\hline
\end{tabular}

GIT: Gastrointestinal tract, NSAIDs: Nonsteroidal anti-inflammatory drugs

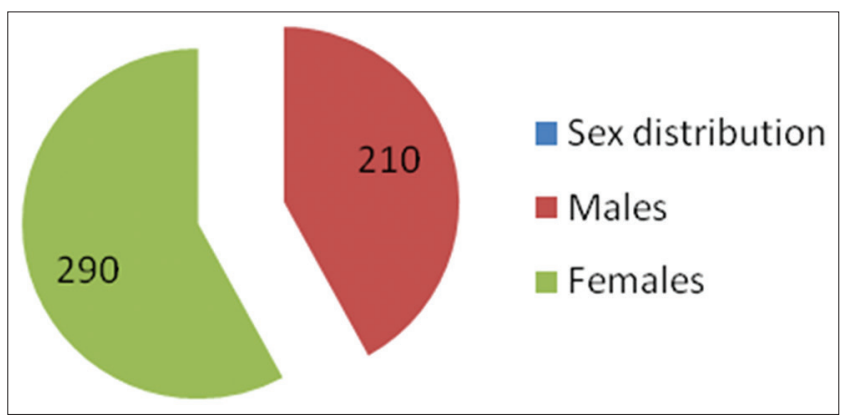

Fig. 1: Gender wise distribution of patients

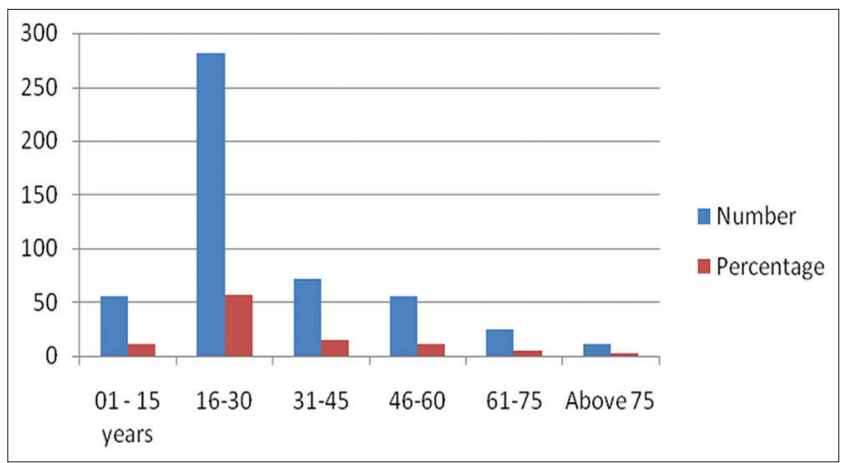

Fig. 2: Age wise distribution of patients
In our study, the total number of drugs in 500 prescriptions analyzed was 1127. Therefore, average number of drugs/prescription is 2.25 . This number is almost equal to the WHO recommended a limit of 2.0 [7].

Increase in the number of average drugs per prescription may increase the risk of drug interactions, may lead to unwanted side effects and also increases the prescribing and dispensing errors. However, in certain conditions like cardiovascular problems, the patients may require more than one drug.

The recently published Seventh Report of the Joint National Committee on prevention, detection, evaluation, and treatment of high blood pressure guidelines also permit polypharmacy in hypertension [8].

Drugs were prescribed by generic names in only $7.98 \%$ of cases. This figure is very low as compared to other Indian studies many of which have even reported up to $73.4 \%$ usage of generic name [9]. This clearly shows how our prescribing habits are being directly influenced by the representatives of the drug companies for undue favors. Generic prescribing reduces the chances of dispensing errors which may be due to misinterpretation of sounding names of drugs and also decreases the economic burden on the patients. Hence, we should encourage generic prescribing by educational intervention methods and strict compliance to the WHO drug policies. We should organize seminars and other programs to sensitize the prescribing clinicians/health-care professionals.

Drugs prescribed from National List of Essential Medicines were about $97.07 \%$. It was higher when compared to other studies $[10,11]$. Around $92 \%$ of drugs were prescribed as oral formulations, 3.37\% of drugs as injectables, and $4.43 \%$ as topical formulations. Prescription of injectables was less when compared to other two Indian studies which reported $7 \%$ and $6.8 \%$ use of injectables, respectively [12,13]. We need to reduce the unnecessary use of injectables to prevent HIV and other blood-borne infections [14].

FDCs of antibiotics are highly popular in the Indian pharmaceutical market. Studies are showing extensive use of a fixed dose of antimicrobials in developing countries. Though WHO has approved only 25 FDC in the 15 th edition of the WHO essential drugs list $[15,16]$. In our study, overall FDCs used were in $15.7 \%$ of prescriptions. This figure is comparatively similar with other studies [17]. Increased use of FDCs may warrant inappropriate use of unwanted drugs which can lead to adverse effects and drug interactions. Use of FDCs should be discouraged unless strictly necessary.

Antibiotics prescribed were $12.42 \%$ of total drugs. This result is acceptable and as compared to a study by Gupta et al. in which half of the

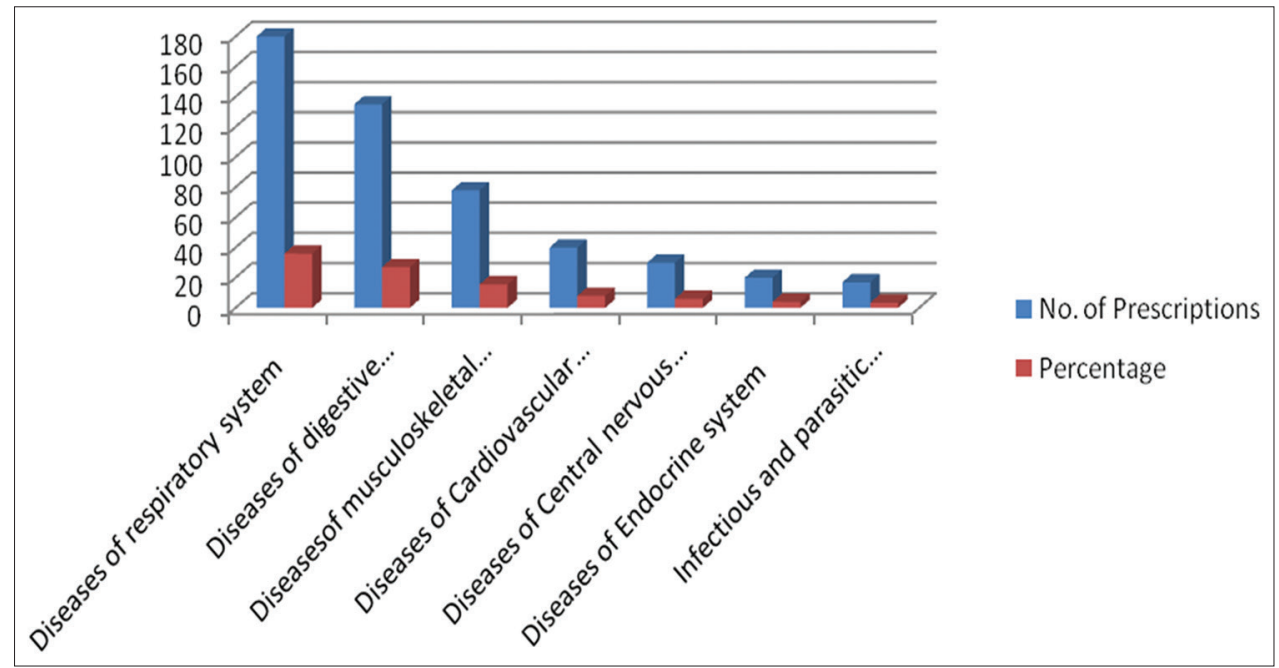

Fig. 3: Disease pattern in patients 


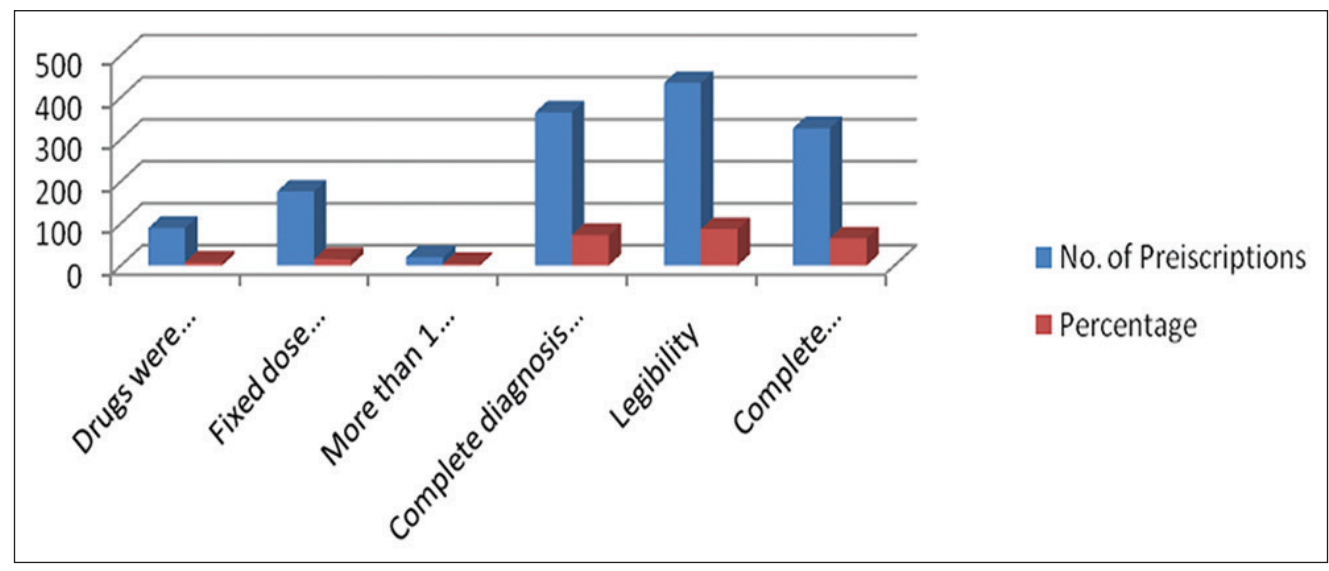

Fig. 4: Prescription profile of the patients

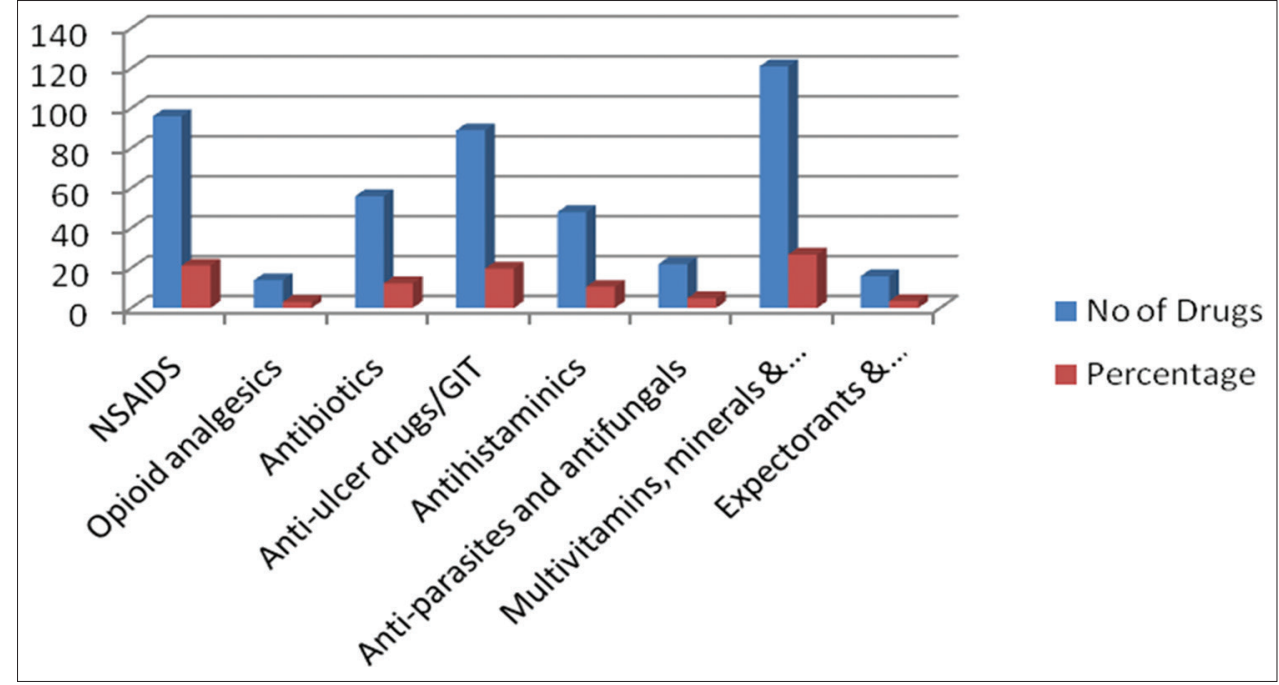

Fig. 5: Most frequently prescribed categories of drugs

patients, i.e., $50 \%$ received more than one antibiotic this figure is much lower [18]. According to the WHO, in developing countries, $15-25 \%$ of prescriptions with antibiotics are expected where infectious diseases are prevalent [19]. Previous studies reported that the use of antibiotic was $78 \%$ in Bangladesh, whereas it varied from 40 to $80 \%$ in India. In one study, the percentage of prescriptions with antibiotics was $54 \%$ which is less but do not comply the WHO standard [20]. Appropriate use of antibiotics is absolutely necessary to prevent the emergence of drug resistance and should be mostly used after culture sensitivity testing. Most of the acute respiratory and acute gastroenteritis cases are viral in nature and may not need antibiotics. An antibiotic policy should be formulated so that the clinicians can use them judiciously according to patients need.

Completeness in terms of dose, route, strength, and frequency and dosage forms was seen only in $65.4 \%$ of prescriptions and with complete diagnosis $73 \%$. All these information should be complete in all respects. Only $87 \%$ of prescriptions were legible. Therefore, proper training and education of physicians are necessary regarding legibility and completeness of prescriptions in all aspects. The most common disease pattern seen in patients attending our hospital was diseases of respiratory system accounting for $36 \%$ of cases followed by diseases of gastrointestinal system which were $27 \%$, and diseases of musculoskeletal system were $15.6 \%$ of cases.

The most common categories of drugs prescribed were multivitamins, minerals, and enzymes, i.e., $26.82 \%$ followed by NSAIDs which were $21.28 \%$, antiulcer drugs $19.73 \%$, antibiotics $12.41 \%$, and antihistamines were $10.64 \%$. Doctors should not prescribe unnecessary medicines such as multivitamins, minerals, and enzymes unless absolutely required by the patient. They should adhere and prescribe from the National List of Essential Medicines.

\section{CONCLUSION}

The present study suggests that there is an immense scope of improvement in a prescription pattern in the hospital. Majority of drugs $(92.07 \%)$ were prescribed by the branded names, hence, there is an urgent need for prescription of drugs by generic names. Polypharmacy was not observed antibiotic usage, use of dosage formulations, FDCs, prescription of drugs from National List of Essential Medicines, etc., were almost in line with the WHO recommendations. Other parameters such as complete diagnosis and legibility of prescriptions need to be improved.

To improve the quality of care, an action plan should be formulated with recommendations for changing the present prescribing practices by providing the hospital doctors with the standard treatment guidelines, National Essential Medicine List, and antibiotic policy.

\section{ACKNOWLEDGMENT}

I would like to thank ICMR for approving the project and also would like to express my gratitude to our professor Dr. Ramesh for his scientific inputs and constant encouragement. Last but not the least, I would like to thank Miss Siwani Teki, who was instrumental in the project. 


\section{AUTHORS CONTRIBUTIONS}

Dr. A Naveen raised the idea, designed the study and participated in statistical analysis and drafted the manuscript; Dr. B Ramesh participated in the study conception and manuscript revision; Mis. Teki siwani, collected the data from the hospital and also involved in statistical analysis.

\section{CONFLICT OF INTERESTS}

All authors have none to declare.

\section{REFERENCES}

1. Enato EF, Chima IE. Evaluation of drug utilization patterns and patient care practices. West Afr J Pharm 2011;22:36-41.

2. WHO. World Health Organization Medicine Strategy, 2008-2013. Geneva: WHO; 2008.

3. Kastury N, Singh S, Ansari KU. An audit of prescription for rational use of fixed dose drug combinations. India J Pharmacol 1999;31:367-9.

4. Thomas M,Alexander B, Tony S, Andrei Z. Guidelines for Implementing Drug Utilization Review Programs in Hospital. Arlington, VA, Moscow, Russia: Management Sciences for Health; 1997.

5. WHO. Model List of Essential Drugs. Geneva: World Health Organization; 1988.

6. Hogerzeil HV. Promoting rational prescribing: An international perspective. Br J Clin Pharmacol 1995;39:1-6.

7. World Health Organization. How to Investigate Drug Use in Health Facilities, Selected Drug use Indicators, WHO/DAP/93.1. Geneva: WHO; 1993.

8. Chobanian AV, Bakris GL, Black HR, Cushman WC, Green LA, Izzo JL, et al. The seventh report of the joint national committee on prevention, detection, evaluation, and treatment of high blood pressure. JAMA 2003;289:2560-71.
9. Karande S, Sankhe P, Kulkarni M. Patterns of prescription and drug dispensing. Indian J Pediatr 2005;72:117-21.

10. Biswas NR, Jindal S, Siddiquei MM, Maini R. Patterns of prescription and drug use in ophthalmology in a tertiary hospital in Delhi. Br J Clin Pharmacol 2001;51:267-9.

11. Hazra A, Tripathi SK, Alam MS. Prescribing and dispensing activities at the health facilities of a non-governmental organization. Natl Med J India 2000;13:177-82.

12. Rishi RK, Sangeeta S, Surendra K, Tailang M. Prescription audit: Experience in Garhwal (Uttaranchal), India. Trop Doct 2003;33:76-9.

13. Maini R, Verma KK, Biswas NR, Agrawal SS. Drug utilization study in dermatology in a tertiary hospital in Delhi. Indian J Physiol Pharmacol 2002;46:107-10.

14. Hutin YJ, Hauri AM, Armstrong GL. Use of injections in healthcare settings worldwide, 2000: Literature review and regional estimates. BMJ 2003;327:1075.

15. WHO. WHO Drug Information. Geneva: WHO; 2003. Available from: http://www.apps.who.int/medicinedocs/en/d/Js4955e/7.html. [Last accessed on 2015 Mar 12].

16. Gor AP, Ajbani A, Dalal K. Use of fixed dose combinations of antibiotics in a surgical department of a tertiary care teaching hospital. Int J Pharm Pharmsci 2015;7:259-62.

17. Chakrabarti A. Prescription of fixed dose combination drugs for diarrhoea. Indian J Med Ethics 2007;4:165-7.

18. Gupta N, Sharma D, Garg SK, Bhargava VK. Auditing of prescriptions to study utilization of antimicrobials in a tertiary hospital. Indian $\mathrm{J}$ Pharmacol 1997;29:411-5.

19. Lamichhane DC, Giri BR, Pathak OK, Panta OB, Shankar PR. Morbidity profile and prescribing patterns among outpatients in a teaching hospital in Western Nepal. Mcgill J Med 2006;9:126-33.

20. Datta SK, Paul TR, Monwar M, Khatun A, Islam MR, Ali MA, et al. Patterns of prescription and antibiotic use among outpatients in a tertiary care teaching hospital of Bangladesh. Int J Pharm Pharm Sci 2016;8:60-3 